\title{
Mallory's ('alcoholic') hyaline in primary biliary cirrhosis
}

\author{
RODERICK N. M. MacSWEEN
}

From the University of Glasgow, Department of Pathology, The Western Infirmary, Glasgow

SYNOPSIS Mallory's ('alcoholic') hyaline has been found in hepatocytes in 18 of 70 patients with primary biliary cirrhosis. These inclusions have previously been noted in only three cases of primary biliary cirrhosis. Current views on the nature of Mallory's hyaline are briefly discussed.

Mallory, in 1911, first described the presence of hyaline material in the cytoplasm of liver cells, especially in cases of alcoholic cirrhosis. This material comprises an eosinophilic ramifying meshwork predominantly distributed around the nucleus of the hepatocyte. Its high incidence is of considerable help in the diagnosis of alcoholic liver disease. However, similar inclusions have also been described in Indian childhood cirrhosis (Smetana, Hadley, and Sirsat, 1961 ; Nayak, Sagreiya, and Ramalingaswami, 1969), Wilson's disease (Popper, 1968), benign and malignant hepatocellular tumours (Edmondson, 1958; Norkin and Campagna-Pinto, 1968), and also in end-stage cirrhosis of varying aetiology (Baggenstoss and Stauffer, 1952; Popper, Rubin, Krus, and Schaffner, 1960; Becker, 1961; Scheuer, 1968). In the present communication the occurrence of hyaline in hepatocytes in primary biliary cirrhosis is reported.

\section{Materials and Methods}

Liver biopsy and/or necropsy material was available from 70 patients in whom the clinical, biochemical, serological, and histological findings were consistent with a diagnosis of primary biliary cirrhosis (Goudie, MacSween, and Goldberg, 1966; Scheuer, 1967; Sherlock, 1971). Paraffin-embedded sections of these were routinely stained with haemalum and eosin (H \& E), Masson's trichrome, Gordon and Sweet's reticulin, periodic acid Schiff (PAS), and Perls' iron reaction.

\section{Results}

Mallory's hyaline was present in hepatocytes of 18 in the 70 patients, an incidence of $26 \%$. In none of Received for publication 1 March 1973. these patients was there a documented history of ${ }_{z}^{-}$ alcoholic abuse. In 12 of these the hyaline was noted in biopsy material, in four it was noted in necropsy material, none having been detected in an earlier $\stackrel{\oplus}{+}$ biopsy, in one instance it was present in both necropsy. ${ }^{\omega}$ material and in a biopsy taken three years earlier, and in one hyaline was identified in postmortem liver, there having been no earlier biopsy. The hyaline bodies tended to occur in groups, in areas adjacent to portal tracts and connective tissue septa. Cirrhosis $\stackrel{\mathbb{\Omega}}{\Omega}$ was established in 17 of the 18 livers examined. The $\vec{F}$ exception was a female of 29 in whom the only3 clinical features of her liver disease were a mildJ degree of pruritus and hepatomegaly, but in whom: the biopsy showed typical features of early primary biliary cirrhosis. In none of the livers was there any? significant degree of fatty infiltration.

In five instances hyaline deposits were present in fairly considerable amounts, but in the remainder ${ }_{3}^{\circ}$ there were only scanty to moderate deposits. In the one patient in whom hyaline was seen in both biopsy? and necropsy material considerably greater amounts were present at necropsy. The typical features of primary biliary cirrhosis noted in the biopsy in this patient are shown in fig 1 , and in fig 2 the hyaline deposits in hepatocytes are illustrated.

The presence of hyaline did not correlate with anyw other clinical or biochemical parameter of the disease.

\section{Discussion}

There are only brief references in the literature to the occurrence of Mallory's ('alcoholic') hyaline in primary biliary cirrhosis. Becker (1961) noted hyalinen in six of 13 non-alcoholic white South Africans witle biliary cirrhosis, but of unspecified type. Ament and Fenster (1970) reported Mallory's hyaline in hepato를 


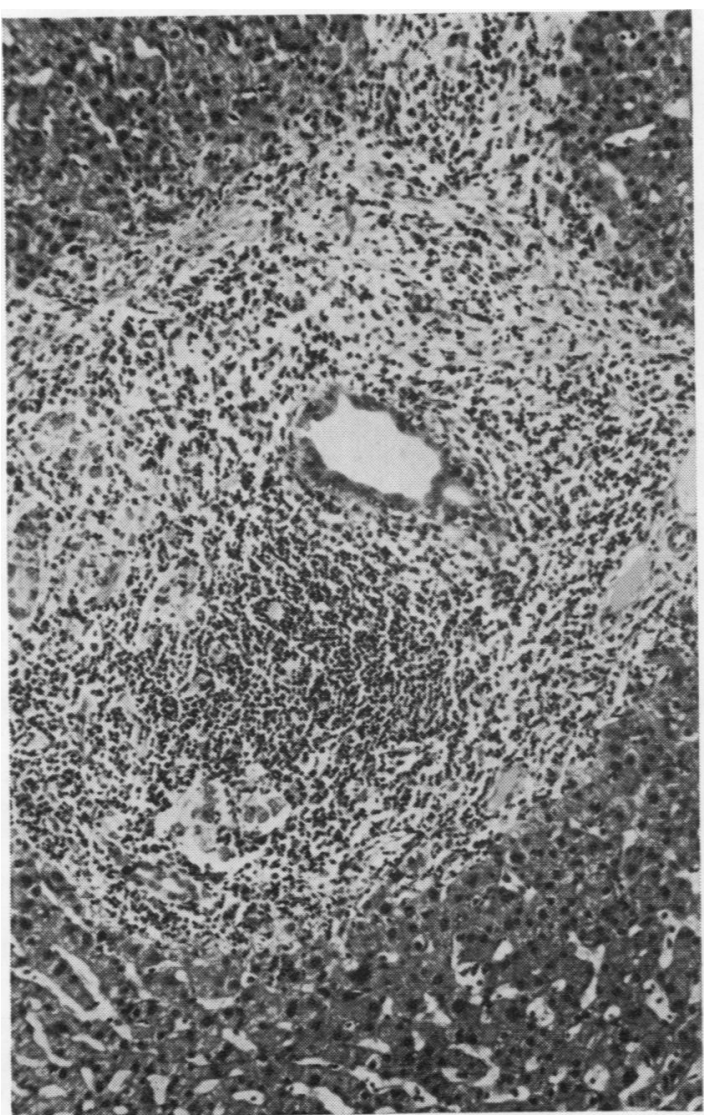

Fig 1

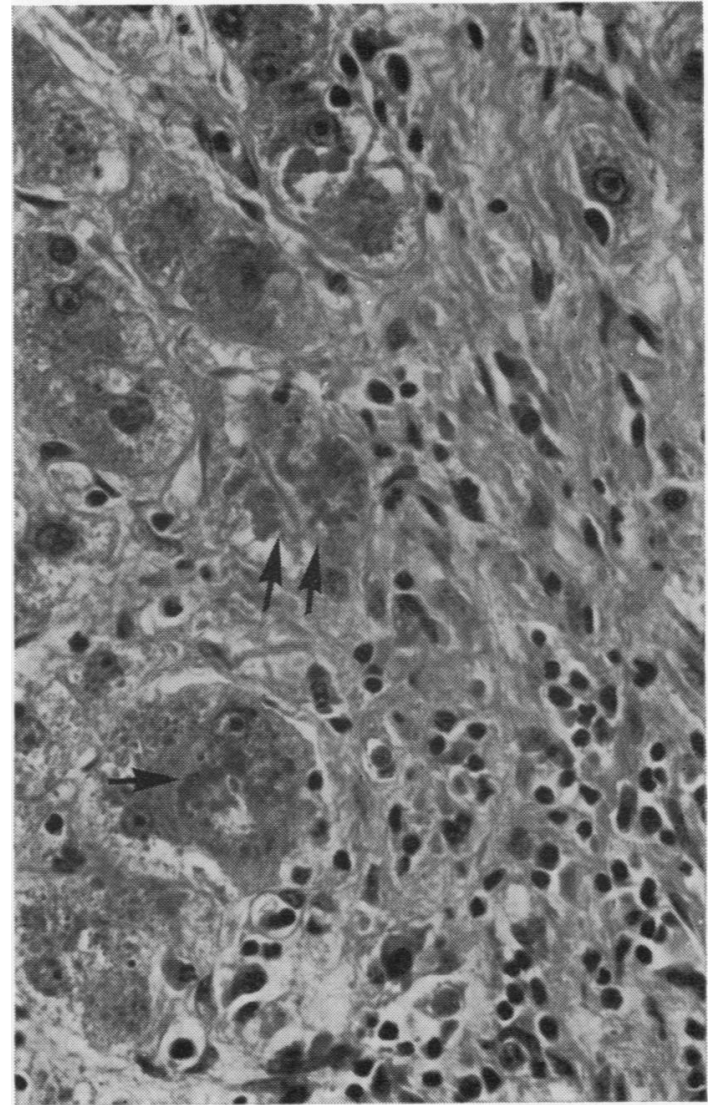

Fig 2

Fig 1 Liver biopsy showing typical features of primary biliary cirrhosis with involvement of a small bile duct, a diffuse and focal chronic inflammatory cell infiltrate of the portal area, and a small giant cell granuloma. Haematoxylin and eosin $\times 66$.

Fig 2 Liver from necropsy of same patient showing hyaline inclusions (arrowed) within a number of hepatocytes. Haematoxylin and eosin $\times 266$.

cytes from three patients with chronic cholestasis, and in whom the overall histological appearances were compatible with primary biliary cirrhosis. Keeley, Iseri, and Gottlieb (1972) found typical hyaline inclusions in a liver biopsy from a 62-yearold woman with primary biliary cirrhosis and in whom none were seen on biopsy six years previously. Popper (1971) demonstrated the presence of hyaline in chronic aggressive hepatitis and observed that its occurrence in mechanical biliary obstruction and in bile infarcts was now recognized.

The distribution of the hyaline in the present material was adjacent to portal tracts and connective tissue septa, and corresponded to the distributional pattern of peripheral cholestasis which is seen in primary biliary cirrhosis. However, in no instance were any hepatocytes seen which contained both retained bile and hyaline. Whether there is a direct relationship between the hyaline and the cholestasis is not readily apparent.

The nature and origin of hyaline inclusions, while of considerable interest to hepatologists, still remain in doubt. Their distribution and tinctorial properties are well documented, and on electron microscopy they have been shown to have a distinct fibrillar character (Biava, 1964; Flax and Tisdale, 1964; Smuckler, 1968; Iseri and Gottlieb, 1971; Yokoo, Minick, Batti, and Kent, 1972). Whereas some workers have suggested an origin from giant mitochondria (Porta, Bergmann, and Stein, 1965; Steiner, Jézéquel, Phillips, Miyai, and Arakawa, 1965), more recent observations seem to leave little doubt but that the hyaline has no limiting membranes and is readily distinguished from such organelles 
(Iseri aud Gottlieb. 1971; Yokoo et al, 1972). Biava (1964) suggested that the deposits represented altered granular reticulum and ribosomes. However, Yokoo et al (1972) found no evidence to suggest that the deposits resulted from products of cellular degeneration, and they postulated that it was synthesized de novo. These workers considered that the electron microscopic morphology of hyaline was consistent with its belonging to the category of contractile cytoplasmic filaments.

The finding of hyaline deposits in the liver in primary biliary cirrhosis further emphasizes that they are probably not pathognomonic of alcohol abuse, and it would seem appropriate that the description 'alcoholic hyaline' be no longer used. However, the nature of this peculiar reaction of the hepatocyte to injury in a number of different disease processes is not clear; its functional significance (if any) and the mechanisms of its formation remain to be elucidated.

\section{References}

Ament, M., and Fenster, L. F. (1970). Mallory bodies in chronic cholestasis. (Abstr.) Gastroenterology, 58, 278.

Baggenstoss, A. H., and Stauffer, M. H. (1952). Posthepatitic and alcoholic cirrhosis: clinico-pathologic study of $\mathbf{4 3}$ cases of each. Gastroenterology, 22, 157-180.

Becker, B. J. P. (1961). The nature of alcoholic hyaline. Lab. Invest., 10, 527-534.

Biava, C. (1964). Mallory alcoholic hyalin: a heretofore unique lesion of hepatocellular ergastoplasm. Lab. Invest., 13, 301-320.

Edmondson, H. A. (1958). Tumours of the Liver and Intrahepatic Bile Duct. Atlas of Tumor Pathology, Sect. VII, fasc. 25. Armed Forces Institute of Pathology Washington, D.C.

Flax, M. H., and Tisdale, W. A. (1964). An electron microscopic study of alcoholic hyalin. Amer. J. Path., 44, 441-454.

Goudie, R. B., MacSween, R. N. M., and Goldberg, D. M. (1966). Serological and histological diagnosis of primary biliary cirrhosis. J. clin. Path., 19, 527-538.

Iseri, O. A., and Gottlieb, L. S. (1971). Alcoholic hyalin and megamitochondria as separate and distinct entities in liver disease associated with alcoholism. Gastroenterology, 60, 1027-1035.

Keeley, A. F., Iseri, O. A., and Gottlieb, L. S. (1972). Ultrastructure of hepatocytic cytoplasmic inclusions in a case of primary biliary cirrhosis: relationship to Mallory's alcoholic hyalin. (Abstr.) Gastroenterology, 62, 179.
Mallory, F. B. (1911). Cirrhosis of the liver: five different types of lesions from which it may arise. Bull. Johns Hopk. Hosp., 22, 69-75.

Nayak, N. C., Sagreiya, K., and Ramalingaswami, V. (1969). Indian childhood cirrhosis: the nature and significance of cyto= plasmic hyaline of hepatocytes. Arch. Path., 88, 631-637.

Norkin, S. A., and Campagna-Pinto, D. (1968). Cytoplasmic hyaline inclusions in hepatoma. Arch. Path., 86, 25-32.

Popper, H. (1968). Comments. In Wilson's Disease (Birth Defects Original Article Series, Vol. 4, No. 2, edited by D. Bergsma), $\varrho$ p. 103. National Foundation, New York.

Popper, H. (1971). Morphological and immunological studies on ${ }^{\mathscr{C}}$ chronic aggressive hepatitis and primary biliary cirrhosis. In $\vec{O}$ Immunology of the Liver, edited by M. Smith and R. Williams, p. 17. Heinemann, London.

Popper, H., Rubin, E., Krus, S., and Schaffner, F. (1960). Postnecrotic $\vec{\omega}$ cirrhosis in alcoholics. Gastroenterology, 39, 669-686.

Porta, E. A., Bergman, B. J., and Stein, A. A. (1965). Acute alcoholic hepatitis. Amer. J. Path., 46, 657-690.

Scheuer, P. J. (1967). Primary biliary cirrhosis. Proc. roy. Soc. Med. مै $60,1257-1260$

Scheuer, P. J. (1968). Liver Biopsy Interpretation. Baillière, Tindall of Cassell, London.

Sherlock, S. (1971). Diseases of the Liver and Biliary System, 4th ed. (revised 3rd printing). Blackwell, Oxford.

Smetana, H. F., Hadley, G. G., and Sirsat, S. M. (1961). Infantile cirrhosis: an analytic review of the literature and a report of 50 cases. Pediatrics, 28, 107-127.

Smuckler, E. A. (1968). The ultrastructure of human alcoholic hyalin Amer. J. clin. Path., 49, 790-797.

Steiner, J. W., Jézéquel, A. M., Phillips, M. J., Miyai, K., ande Arakawa, J. K. (1965) Some aspects of the ultrastructural pathology of the liver. In Progress in Liver Diseases, edited. by H. Popper and F. Schaffner, Vol. 2, 303-372. Grune and Stratton, New York. Heinemann, London.

Yokoo, H., Minick, O. T., Batti, F., and Kent, G. (1972). Morphologic variants of alcoholic hyalin. Amer. J. Path., 69, 25-40.

\section{Addendum}

Since this article was prepared for publication $\overrightarrow{0}$ Gerber and his colleagues (Gerber, Orr, Schaffner, and Popper, 1973) have also drawn attention to hyaline inclusions in primary biliary cirrhosis. They? could not detect a morphological relationshipo between hyalin and cholestasis or any other: hepatocellular abnormalities.

Reference

Gerber, M. A., Orr, W., Denk, H., Schaffner, F., and Popper, H. (1973). Hepatocellular hyalin in and cholestasis cirrhosis: it diagnostic significance. Gastroenterology, 64, 89-98. 